Article

\title{
The Negative Influence of Native-Speakerism on the Sustainability of Linguistic and Cultural Diversities of Localized Variants of English: A Study of Local and Expatriate Teachers in South Korea
}

\author{
Kumju Hwang ${ }^{1}$ and Su Yon Yim ${ }^{2, *(1)}$ \\ 1 Business School, Chung-Ang University, Seoul 06974, Korea; kumju@cau.ac.kr \\ 2 English Education, Chinju National University of Education, Jinju-si, Gyeongsangnam-do 52673, Korea \\ * Correspondence: edu1syy@cue.ac.kr
}

Received: 25 September 2019; Accepted: 22 November 2019; Published: 27 November 2019

\begin{abstract}
This study explores teacher identities of native English-speaking teachers (NESTs) and non-native English-speaking teachers (NNESTs) based on interview data collected from twenty teachers who teach English to young learners in South Korean primary schools. The participants comprised ten NESTs and ten NNESTs. Bourdieu's concept of three pillars was used to explore hegemonic relations between NESTs and NNESTs. The interview analysis showed that two different types of symbolic capital—one specified as native-speakerism and the other concretized as qualified tenured teacher positions-shape the dynamic nature of hegemonic relations that have constructed an antagonistic collective habitus between NESTs and NNESTs. This study revealed that power fluctuations and lack of institutional cultural capital shaped NESTs and NNESTs' fragmented teacher identities which increased their dissatisfaction with their current roles. Bourdieu's concepts provide a sociological vocabulary for understanding NESTs and NNESTs' teacher identities and social status trajectories. This study provides an important theoretical and policy implication that English education practices and policies based on the ideology of native-speakerism fortify students' preference for native English and negative attitudes towards localized variants of English which threatens the sustainability of linguistic and cultural diversities of localized variants of English.
\end{abstract}

Keywords: teacher identity; power conflicts; Bourdieu's concepts: field; capital; habitus; native English-speaking teachers; non-native English-speaking teachers; linguistic and cultural diversities of localized variants of English

\section{Introduction}

As English obtains the status of an international language (EIL) with the number of second-language English speakers outnumbering native speakers [1], the dominance of norms of British and American native-speakers in English-language teaching (ELT) practices is being challenged [2]. The new paradigm of EIL in ELT rejects the ideology of native-speakerism which assumes that native speakers and their cultures have superiority and authority. This phenomenon raises issues of stigmatization of non-native English speakers, categorization of English users, language ownership and identities, respect for cultural diversities [3], and negative impacts of native-speakerism on non-native diverse cultures and their cultural sustainability. In particular, the categorization of English users commonly classified into native and non-native speakers constructs power relations such that native speakers have prestigious power whereas non-native learners imitate not only native speakers' English but also their norms and cultures [4]. The ideology of native-speakerism reflects the view that native English is prestigious and correct [5]. On the other hand, in the EIL context, non-native varieties 
of English have been developed and are increasingly being recognized as variants of English [4]. Although local variants of English are increasingly obtaining their status and importance, the ideology of native-speakerism still threatens the sustainability of cultural diversities, because it creates a negative attitude among second language users towards localized varieties of English as well as a preference for native English [6]. Kabel [7] emphasized that native-speakerism creates "realities of exclusion, discrimination and rationalizations for intervention and cultural correction" (p. 17). To address the problems of native-speakerism in ELT practices and policies, a commonly recommended proposal is that a localized model, linguistically, culturally, and politically more effective for English teachers and learners in the local context, should be applied instead of a native-speaker model [8].

Guo and Beckett [9] argued that English language led neocolonialism and forced English learners to accept and prefer an unfamiliar pedagogical and social culture based on British and American English which greatly threatens the sustainability of learners' languages, cultures, and identities. The linguistic imperialism also suggests that the viewpoint of English education enterprise affects the cultural integrity of non-native speakers. Emphasizing second-language speakers' near-native proficiency in ELT practices and policies forces learners to become auxiliary members of the culture that represents the traditional native English speakers and plays a role in cultural indoctrination [2]. Thus, ELT practices and policies based on the ideology of native-speakerism greatly threaten linguistic and cultural diversities and their sustainability.

In many Asian countries, the powerful hegemony of English language greatly affected ELT policies [10]. Influenced by the ideology of native-speakerism, the governments of some Asian countries, such as Hong Kong, Japan, Korea, and Taiwan, have established policies of actively recruiting NESTs to improve English education [11,12]. However, Wang and Lin [11] found problematic results including a poor quality of English instruction, damaged professional identities among NNESTs, and the recruitment of unqualified and inexperienced NESTs. Teachers' professional identities constructed through well-designed training and certification lead teachers to perform better [13]. However, because of the limited recruitment pool, most expatriate NESTs in these countries are not expected to possess a professional identity as teachers (i.e., most expatriate NESTs are unqualified and inexperienced teachers) when they are recruited. In this case, their teacher identities can be cultivated during co-teaching practices, interactions with NNESTs, and participation in the local English teacher community. Thus, it is necessary to investigate how NESTs' teacher identities are cultivated or impeded in the context of the prevalent co-teaching practices between NESTs and NNESTs [14]. Additionally, one needs to examine how NNESTs' professional teacher identities are challenged and damaged in the co-teaching processes with NESTs based on native-speakerism ideology.

In the ideological relation based on native-speakerism, NESTs are believed to enjoy superiority as legitimate English teachers whereas NNESTs are considered to be disempowered because of the label of "non-nativeness" in the English teaching community. Richards [15] argued that NESTs working in a foreign country "are sometimes credited with an identity they are not really entitled to" (p. 111) which is regarded as the "native-speaker as expert syndrome". Wang-McGrath [16] supported Richards' point by arguing that expatriate NESTs have linguistic and sociocultural power over local NNESTs (p. 44) which is why the position of NNESTs has been frequently examined within the framework of "hegemonic relations" between NESTs and NNESTs [17]. These hegemonic relations reflect NNESTs' fear of losing their value as English teachers and entail a power struggle to maintain their legitimate status as English teachers.

However, in the case of expatriate NESTs, the power structure in the co-teaching environment is more complex because expatriate NESTs have to work with NNESTs who have different sources of power such as teaching qualifications and local knowledge. Jeon (2009) [18] criticized the simplistic view of NESTs as beneficiaries of the ideology of native-speakerism and argued that NESTs also experience marginalization in their interaction with NNESTs and students. According to Kim (2012) [19], NESTs perceive themselves as proficient teachers in the classroom but feel like outsiders outside it. 
To understand these hegemonic relations between NESTs and NNESTs [17] who possess different power sources and compete by valuing their own power sources to produce and reproduce legitimate and superior status in the classroom, organization, and community, Bourdieu's concepts of field, capital, and habitus might be useful. The NNESTs previously had been regarded as legitimate teachers because of their institutional cultural capital (e.g., educational background and teacher certification). However, NESTs with English native-speaker status, or native-speakerness, a powerful linguistic capital in the field of English education, have threatened NNESTs' reproduction of their legitimate status as English teachers in this field. Accordingly, power conflicts stemming from competing valuations of their respective strong capitals may be inevitable. Moreover, the different strengths of NESTs and NNESTs in terms of co-teaching practices are expected ideally to yield synergetic effects. However, teacher autonomy, particularly considered as a direct and explicit link to teacher professional identity [20], may impede such synergism. Their different cultural capitals can work to cause them to become mutually autonomous professional teachers, often threatening their identity as teachers as they feel disrupted or imperfect. Achieving teacher autonomy might entail devaluing the capital of their counterparts. Thus, this study explores the construction and replication of NESTs' and NNESTs' teacher identities during their co-teaching practices, as well as their power conflicts, through Bourdieu's three pillar concepts-field, capital, and habitus. Previous studies mostly documented the problem of native-speakerism in terms of learners' preference for native English and their negative attitude towards local variants of English. The current study focused on the influence of native-speakerism on both native and local English teachers' fragmented professional identities and anxiety.

\section{Theoretical Background}

The implementation of NEST recruitment policies changes the field of English education as a site for the distribution of power and social control [21]. The NESTs entered the existing field of NNESTs, parents, students, government agencies, private educational institutes, and civic group, and consequently, new struggles for the power and social control ensued. Though previous studies of cultural capital in the field of education have mainly focused on students [22], this study focuses on the social relations between NESTs and NNESTs, who have been greatly affected by this policy in terms of their teaching culture, practice, and identity. Hence, this study concentrates on the field of English teaching.

Drawing from Bourdieu's conceptual framework, the hegemonic relations reported between NESTs and NNESTs $[17,23-26]$ can be analyzed in terms of differences in their opportunities to access capital and the distribution of their symbolic capital which depend on their relative power in this specific field. As Bourdieu and Wacquant [27] argued, the types of capital and the field are interrelated, and capital confers power over the field. The concept of the field is relational or dialectical [28] and focuses on power, domination, and class [29]. The forms of capital are field-specific, and in the field of teaching, intangible cultural capital—including knowledge, skills, lifestyle, qualifications-holds great significance [30]. The field of English teaching has two prominent forms of cultural capital that confer power over the field and constitute forms of symbolic capital that provide participants with legitimacy: linguistic capital, which is a form of embodied cultural capital [31] that refers to "external wealth converted into an integral part of the person" [32] (p. 244); and institutional cultural capital, which indicates "officially recognized, guaranteed competence" (p. 243), exemplified by academic certifications or technical qualifications [33]. Linguistic capital in the field of English teaching presents as symbolic capital, embodied in the form of reputation, prestige, and authority [29], which shapes the way "in which social fields are organized as particular hierarchies of positions and capital" [33] (p. 169) through the prevalent ideology —native-speakerism—while institutional capital includes teacher certificates and educational background. Institutional cultural capital is embodied in tenured teacher positions in the organization, in contrast to contract teacher positions. The policy forced the rules of the game to be re-written in this field, and the convergence of the power held by NNESTs has been divided between NESTs, who possess linguistic capital based on native-speakerism, and NNESTs as tenured 
teachers. Accordingly, the re-distribution of power and power struggles $[25,26]$ to gain legitimacy continue [23,24].

Though Bourdieu's constructivist structuralism includes concepts such as field, capital, habitus, doxa, symbolic violence, etc., the three concepts of capital, habitus, and field are widely recognized as Bourdieu's master concepts [34]. As these concepts are intertwined, they need to be analyzed relationally, though research in cultural capital as a stand-alone tool to understand the social world of the field of education seems prevalent in the sociology of education [34]. Bourdieu writes of Habitus as "a system of lasting, transposable dispositions which, integrating past experiences, functions at every moment as a matrix of perceptions, appreciations, and actions" [35] (pp. 82-83). In the absence of a clear definition, habitus has been extended and diversely applied [36] and remains ambivalent [37], so that it has come to include varying elements, such as cultural codes as collective habitus, individual social actors' dispositions, perceptions of the field [35], identity related to the field [29], and values, beliefs, and norms [38]. As "the product of the internalization of the structures" of the social world [39] (p. 18), habitus naturally includes the individual social actor's identity [40]. It is a tool to analyze the social world within the structure of a field with small-scale interactions between social actors and their behavior within large-scale settings [41], linking individual social actors as a micro form to the field as macro structure. Habitus is not fixed and is subject to change and modification depending on changes in the field and struggles over capital arising as the field changes [29]. Habitus incorporates the duality of individualized and collective elements; most studies try to embody this duality, and some research has shown the interactions between the individual and the class collective [41]. However, educational research has not produced many empirical studies of habitus because of the difficulty of operationalizing it [41]. Previous studies, such as those focusing on individual dispositions of habitus [42], the educated habitus of individual and working-class interactions [43], and the operationalization of habitus as students' occupational aspirations [44], present a diverse range of focuses on habitus. The difficulty in operationalizing habitus because of its broad and ambivalent nature demonstrates that holistic and comprehensive views of habitus may hinder its empirical study; instead, a study of habitus within the narrowly focused aspects peculiar to a specific field [36] and context may be more appropriate. Accordingly, this study explores the habitus focused on NESTs' teacher identities and the collective habitus shaped by their social status in terms of the two prominent cultural capitals, their roles in the classroom, and interactions and power struggles with NNESTs in the field of English teaching.

Regarding the prominent cultural capitals in this field, non-native speakers have been treated as second-class citizens within the perspective of native-speakerism [45], though the dichotomy based on native-speakerism has been criticized [46]. Accordingly, native-speakerness plays the role of reproducing unequal and oppressive social orders in the field [47]. Thus, English native-speakerness can be viewed as linguistic capital in the form of embodied cultural capital that reproduces the inequalities in the field. The prevalent perception of standard English reflects the notion that largely monolingual native-speakers who are white and middle class own the English language and draw legitimacy through this "native" form of the language [48]. Pavlenko [47] found that English education has led some students to believe that the white majority exclusively owns the English language and to perceive African American English as erroneous and inferior. Accordingly, native-speakerism incorporates the class collective habitus at the nation-wide and ethnic levels.

From the perspective of institutional cultural capital, NESTs are employed as contract teachers in distinction to tenured teachers, reflecting their lack of institutional cultural capital, while NNESTs are tenured teachers. Contract teachers commonly perceive themselves as second-class citizens in their organizations because of their employment instability and low status in the profession and sometimes feel exploited and unfairly treated [49]. Govinda and Josephine [50] found that contract professionals feel discriminated against by tenured professionals; and contract teachers have some psycho-social and financial barriers [51] and difficulties in interpersonal relationships with tenured colleagues. As contract teachers, NESTs may encounter problems similar to other contract teachers 
and perceive themselves as second-class citizens. Accordingly, institutional cultural capital empowers NNESTs in this field and reproduces an unequal social order. Therefore, the tenured-contract teacher positions, as field-specific collective class habitus, frame the structure of the field.

Post-structuralists such as Bourdieu [35], Norton [52], and Zembylas [53] highlighted the place of power in identity construction. For example, Norton states that "relations of power can serve to enable or constrain the range of identities" [52] (p. 9). This relates to Zembylas' argument that 'teacher identity is constantly becoming in a context embedded in power relations, ideology, and culture' [53] (p. 213). Bourdieu's notion of power as a relational or process-oriented function through a multiplicity of relations in the field can be useful in analyzing the power struggle of organizational actors in accumulating capital [28]. Bourdieu introduced the notion of symbolic capital to explain power relations in a society [32]. According to Bourdieu [32], symbolic capital is what a dominant group authorizes as legitimate. As cultural capital is converted to symbolic capital when regarded as legitimate, symbolic capital may be the most valuable capital and the foundation of the ultimate basis of durable power [29]. The NESTs' linguistic capital becomes symbolic capital when English-nativeness is highly valued, while NNESTs' institutional cultural capital can be converted into symbolic capital when their qualified tenured teacher position is valued. In hegemonic relations, both NESTs and NNESTs may suffer power fluctuations and teacher identity crises. Thus, this study adopts poststructuralism which challenges binary structural dichotomies and maintains that categories and meanings are continuously shifting. This view flows into Foucault's [54] argument that power is by nature shifting and dispersed in discursive practices. According to him, power differentials are not stable; one who has power may be powerless in one context but not in another. Zembylas [53] also argued that power relations influence the process of shaping teachers' identities. Both NESTs and NNESTs may have identity crises which reflects the fact that neither party can have teacher autonomy and a holistic teacher identity.

In teacher education, identity has begun to receive more attention $[25,55]$. Even with a growing trend towards studies of identity in teacher education, the identity of expatriate NESTs has rarely been addressed in the literature. Instead, studies on NESTs have focused mainly on issues like lack of collaboration [56], communication problems [57], ambiguous teacher roles [58], cultural differences [59], and the challenges they encounter while working in foreign countries $[60,61]$. The issues from previous studies imply that NESTs may have difficulties in forming teacher identities. The limited discussion of NESTs might stem from the description of NESTs as empowered in the English teaching profession. Trent's [25] study is one of the few to address NESTs' identity in terms of power conflicts. Trent showed how key stakeholders in their schools challenge NESTs' self-positioning as professional language teachers thereby leading to power conflicts between NESTs and NNESTs. Although his study demonstrated power conflicts between NESTs and NNESTs, it failed to illustrate how the conflicts affected the ways NESTs make sense of themselves as teachers in co-teaching contexts. The current study investigated expatriate NESTs' teacher identities during their co-teaching practices and interactions with NNESTs, as well as their power conflicts with NNESTs, using Bourdieu's concepts of field, capital, and habitus.

\section{The Study}

\subsection{Context}

Pairing native English-speaking teachers (NESTs) and non-native English-speaking teachers (NNESTs) has been common in Asian Pacific countries such as Hong Kong, Japan, South Korea, and Taiwan [14]. According to Carless [14], many unqualified NESTs are hired to teach English in state schools in Korea and Japan. This decreased emphasis on teaching qualifications is obvious when we examine the hiring process of NESTs in those countries. For example, the English Programme in Korea (EPIK) considers nationality as the most important criterion for selecting NESTs. The Korean ELT policy determines the eligibility of NEST candidates for state schools based on citizenship of “Australia, Canada, Ireland, New Zealand, South Africa, the United Kingdom, or the United States" [12] 
(p. 72). Teaching experience is not a deciding factor. These countries belong to the inner circle of Kachru's [62] model, indicating that hiring practices are heavily influenced by native-speakerism, which considers native-speaking teachers ideal for teaching English [63], although the literature challenges this assumption [7].

\subsection{Participants}

Twenty teachers (ten NESTs and ten NNESTs) participated in the study. The NESTs and NNESTs teach English to primary school students from third to sixth grades. Table 1 summarizes the participants' demographic information. For anonymity's sake, interviewees were assigned IDs as shown in Table 1. The participants were recruited on a voluntary basis. All participants were informed that this study was not a part of any project organized by the school or the Ministry of Education (MOE) so as to assure them that their participation would not affect their school life. To approach NEST participants, a recruiting advertisement was posted six weeks before data collection on a popular network website for NESTs in Korea. In the advertisement, the research area and process of data collection were clearly stated, but only two candidates approached us via email to participate in the study. After interviews with the first two participants, a snowball strategy was employed to recruit further participants through word of mouth. Regarding the NNEST participants, the co-teachers of the NEST participants were approached first. It was imperative to include the data from the NNESTs co-teaching with the NEST participants, since power itself is relational and NESTs' identity is constructed through interaction with the NNESTs. Although ten NESTs were involved in the study, only seven were Korean co-teachers, as in some instances two NESTs working in the same school had one Korean co-teacher. For example, NT1 and NT2 were working in the same school with the same co-teacher, NNT1. Two co-teachers of the NEST participants declined to participate in the study. Among the ten NEST participants, seven NESTs (NT1, NT2, NT3, NT4, NT5, NT6, and NT7) had co-teachers among the NNEST participants and the other three did not. The matching co-teaching pairs are listed in the last column of Table 1. Twenty teachers (ten NESTs and ten NNESTs) participated in the study. The NESTs and NNESTs teach English to primary school students from third to sixth grades.

All NEST participants were undergraduate degree holders majoring in different areas. Among the participants, two (NT7 and NT9) majored in education and two (NT8 and NT10) minored in education, which is in contrast with the NNEST participants who held a degree in education and had passed the national qualifying exam to become teachers in state schools. The age of the NEST participants ranged from 26 to 30, whereas the NNESTs participants' ages ranged from 26 to 38. Most NEST participants, except for three (NT2, NT8, NT10), had had no teaching experience before they came to Korea. Their experience with teaching English in Korea varied from 4 to 16 months. Given that the vast majority of NESTs working in Korea have no teaching experience [10], the proportion of participants with teaching experience reflects the research context well. The NNEST participants had experience teaching English that ranged from 1 year 6 months to 11 years. 
Table 1. Demographic information of participants.

\begin{tabular}{|c|c|c|c|c|c|c|c|c|c|}
\hline ID & Gender & Age & Degree & Major & Nationality & $\begin{array}{l}\text { Teaching Experience } \\
\text { before Korea }\end{array}$ & $\begin{array}{l}\text { Teaching Experience } \\
\text { in Korea }\end{array}$ & Certificate & Co-Teacher \\
\hline \multicolumn{10}{|c|}{ NEST } \\
\hline NT1 & F & 30 & BA & Graphic Design & US & None & 4 y 8 months & None & NNT1 \\
\hline NT2 & M & 25 & $\mathrm{BA}$ & English Literature & US & 4 months & 4 y 9 months & TESOL & NNT1 \\
\hline NT3 & $\mathrm{F}$ & 23 & BA & English/Geography & Ireland & None & 9 months & TEFL & NNT2 \\
\hline NT4 & M & 28 & BA & History/English & Canada & None & 2 y 10 months & TESOL & NNT2 \\
\hline NT5 & M & 25 & $\mathrm{BA}$ & English & US & None & 4 months & None & NNT3 \\
\hline NT6 & M & 29 & $\mathrm{BA}$ & Criminal Justice & US & None & 10 months & TESOL & NNT4 \\
\hline NT7 & $\mathrm{F}$ & 24 & BA & Education & US & None & $2 y$ & Teacher certificate & NNT5 \\
\hline NT8 & $\mathrm{M}$ & 25 & $\mathrm{BA}$ & Media Studies/Education & UK & 1 y 4 months & 11 months & Teacher certificate, TEFL & \\
\hline NT9 & $\mathrm{F}$ & 25 & BA & Education & US & None & 2 y 9 months & None & \\
\hline NT10 & $\mathrm{F}$ & 26 & $\mathrm{BA}$ & Political Science/Education & US & $2 y$ & 4 months & TESOL & \\
\hline \multicolumn{10}{|c|}{ NNEST } \\
\hline NNT1 & F & 38 & MA & English Education & Korea & $15 \mathrm{y}$ & 9 y 4 months & Teacher certificate TESOL & NT1, NT2 \\
\hline NNT2 & $\mathrm{F}$ & 38 & MA & English Education & Korea & $16 \mathrm{y}$ & $11 \mathrm{y}$ & Teacher certificate TESOL & NT3, NT4 \\
\hline NNT3 & $\mathrm{F}$ & 35 & BA & English Education & Korea & 9 y 10 months & 6 y 10 months & Teacher certificate & NT5 \\
\hline NNT4 & $\mathrm{F}$ & 31 & $\mathrm{BA}$ & Primary Education & Korea & 5 y 4 months & 3 y 4 months & Teacher certificate & NT6 \\
\hline NNT5 & $\mathrm{F}$ & 38 & MA & Primary Education & Korea & 14 y 10 months & 4 y 3 months & Teacher certificate & NT7 \\
\hline NNT6 & M & 35 & MA & English Education & Korea & 5 y 6 months & 3 y 6 months & Teacher certificate TESOL & \\
\hline NNT7 & $\mathrm{F}$ & 26 & $\mathrm{BA}$ & Primary Education & Korea & 1 y 6 months & 1 y 6 months & Teacher certificate & \\
\hline NNT8 & $\mathrm{F}$ & 34 & MA & English Education & Korea & $12 \mathrm{y}$ & $9 y$ & Teacher certificate TESOL & \\
\hline NNT9 & $\mathrm{F}$ & 35 & $\mathrm{BA}$ & Primary Education & Korea & $11 \mathrm{y}$ & 7 y 5 months & Teacher certificate & \\
\hline NNT10 & $\mathrm{F}$ & 34 & BA & English Education & Korea & $11 \mathrm{y}$ & $4 y$ & Teacher certificate & \\
\hline
\end{tabular}

Note: TESOL: Teaching English to Speakers of Other Languages; TEFL: Teaching English to as a Foreign Language. 


\subsection{Data Collection and Analysis}

Data were collected through semi-structured interviews designed to examine expatriate NESTs and NNESTs' teacher identities as individualized habitus during their co-teaching practices and interactions with NNESTs as well as their power conflicts with NNESTs from the perspective of Bourdieu's concepts. The second author conducted all interviews face to face. Before the interview, interviewees were informed that the data would be used only for research purposes and were asked to sign a consent form. Interview questions assessed their perceived strengths and weaknesses as teachers to understand their social capital; self-perceived position or status in the school; power relationships between NESTs and NNESTs; and their satisfaction as teachers. Interviews lasted $1.3 \mathrm{~h}$ on average. All data were audio recorded and transcribed verbatim. NVivo software was used to enhance the data analysis transparency and rigor of qualitative data analysis [64]. NVivo is appropriate for qualitative data analysis as all codes are linked to data sources. Several types of data analysis were employed in NVivo. First, a keyword search was used to learn how participants used words in context [65]. Second, content analysis was used to capture the prominent themes. We analyzed the data based on the relevant literature. In particular, issues regarding cultural capital, habitus, power, and identity were coded within the participant analysis, and issues that emerged from participants' interviews were compiled to find salient themes that emerged across participants [66]. Finally, these themes were discussed in terms of cultural capital, habitus, and power conflicts that affect NESTs' identity formation and collective habitus. The following section presents the five main themes, including NESTs' linguistic capital (native-speakerness), NNESTs' inferior status, NESTs' inferior status due to the lack of institutional cultural capital (tenured teacher), antagonistic collective habitus, and NESTs' teacher identities, supported by relevant quotes from the interview data. Although the four themes are presented separately, we do not assume that they are separate concepts. The four themes together constitute the identity and collective habitus that help us understand the process of hegemonic relations and social status trajectories.

\section{Findings}

\subsection{Linguistic Capital: Native-Speakerism as the Prevalent Ideology of the English Teaching Field}

Our data show the role of native-speakerism as the linguistic capital that NESTs distinctively possess and as a "guiding ideology of practice" [67] that shapes both NNESTs and students' attitudes towards NESTs and produces shared beliefs, values, and meanings in this field. As students and NNESTs believe in the ultimate value of linguistic competence, linguistic capital becomes symbolic capital in the classroom. Native-speakerism leads to the belief shared by students and NNESTs that only NESTs have a distinctive linguistic competence that NNESTs can never obtain which produces NNESTs' "permanent linguistic insecurity" [68]. Regarding their practical role in the classroom, only NESTs can teach students specific aspects of linguistic competence such as pronunciation and speaking. Native-speakerism as a value and shared belief fortifies social inequality by reproducing NESTs' superior status and maintains their domination in this field. Native-speakerism serves as a collective culture that frames standard English as white middle-class English in this field. Accordingly, native-speakerism in combination with standard English works as collective class habitus in two ways: First, as it provides NESTs' social power over NNESTs, NNESTs become second-class citizens; and second, as non-white middle-class NESTs (e.g., African American or Asian American NESTs) are less preferred by NNESTs, they have inferior status. Thus, native-speakerism shapes three classes: white middle-class NESTs; non-white middle-class NESTs; and NNESTs. In fact, native-speakerism is a multi-layered concept that intertwines individual, nation, ethnicity, and class.

As the guiding ideology and collective class habitus in this field, native-speakerism is acknowledged by NNESTs based on their perception that all NESTs possess a high level of English competence. For example, NNT6 reported, “NESTs' English is 100\% perfect, isn't it?" NNT10 said, "Korean English teachers can never use English well like native-speakers". This point can be analyzed 
by Bourdieu's concept of permanent linguistic insecurity as well [68] which implies that NNESTs' sense of shame over their disparaged accent or linguistic competence and fortifies their inferior social status in this field.

However, N5 pinpointed the multi-layered concept of native-speakerism in saying, "There are many native English speakers who can't speak English". NT10 raised the issue of differences between actual native-speakers and legal native-speakers, stating, "I was actually surprised by a few people in my orientation group that were maybe Americans but just recently became citizens. So sometimes their accents were so inaccurate that I was shocked". In other words, recent USA citizens (for example, non-native English-speaking immigrants with USA citizenship) without proper English competence can become NESTs in Korea because the Korean recruiting system for NESTs works based on applicants' citizenship of the USA or other English-speaking countries rather than their actual English competence. The NESTs' perceptions show that native-speakerism is not based on actual English competence but on nationality which highlights the myth of native-speakerism.

In fact, NESTs possess varying degrees of cultural capital based on their educational background and socioeconomic status. Accordingly, NESTs evaluate other NESTs' English competence on the basis of different types and degrees of capital. For example, NT5 said, "I really and truthfully think that everyone should have at least an English degree. Or, I think history degrees are okay. Political science degrees from the USA, I don't think they should be here. They are terrible writers". NT5 earned his bachelor's degree in English. NT10 also expressed the view that native speakers differ in English speaking levels based on their family background and class. Paradoxically, NESTs are easily employed as English teachers on the basis of native-speakerism, while they emphasized the individualized linguistic competence conferred by institutional cultural capitals and socio-economic factors, including family and class backgrounds, among NESTs.

On the other hand, NESTs recognize that their native-speaker identity presents as symbolic capital that establishes their value as English teachers; for example, NT10 said, 'Native English speakers are the most confident in their English obviously because it doesn't take any thought. And if you put someone in the job who isn't one hundred percent confident about English, then it's going to be hard for her to make their students confident about students' English.' All NEST interviewees considered teaching English pronunciation as their value. Some interviewees even asserted that NNESTs cannot teach pronunciation. NT5 stated, 'The one thing that I don't think they can ever do is teach pronunciation how I can.' NNESTs seem to acknowledge this. According to NT3, her Korean co-teachers let students repeat the pronunciation after NT3, and she claimed that pronunciation is her area of expertise. NT3 explained that, although her Korean co-teachers have very good English skills, their pronunciation is imperfect. Native-speakerism shapes the valuable role of NESTs; they claim it as their asset and NNESTs accept, which produces the practical habitus.

As expected, race produces another class in this field. Expressing her awareness that black Americans are not welcomed by some in Korea, NT9 (black American) shared her experience of rejection:

"Actually, when I first applied for work here, I had a recruiter. I said that I really wanted to be in Seoul. And she replied 'Well, where in Seoul are you thinking?' I said, 'Oh, you know I love Gangnam, it's really nice.' She wasn't sure if she could find me a job in Gangnam though because they only want white teachers."

Being aware of the social prejudice towards African Americans, she reported that she strove to set a good example as a non-Caucasian NEST. She said that she always dresses well for school, possibly in an attempt to compensate for her struggle with legitimacy. NT9 mentioned, "There's a certain kind of legitimacy that comes from being white". This example reflects the perception of standard English as that variety that the white middle class owns. Pavlenko's [47] findings show that English education leads non-native speakers to perceive white middle-class English as the norm of the English language, and NT9's example is a typical case of non-native-speakers' prejudice of African American English 
as erroneous and inferior. To react to Koreans' negative views of her ethnicity, NT9 attempted to act white and middle class to compensate for the alleged illegitimate linguistic properties inferred from her social properties. This point may indicate NT9's mimicry of habitus of the dominant groups of English language, since appearance is a common cultural code.

NNT4 illustrated an interesting example of NNESTs' preference for white NESTs: “The principal really likes NT5 because he is white. Our previous NESTs were Asians. Now we have a handsome Caucasian from the US, so the principal seems to care about him. Other teachers like NT5 a lot too. I think this is based on Korean local teachers' toadyism. Previously they disliked Asian NESTs' accents". NNT4's interpretation of their colleagues' preference as toadyism reflects NNESTs' collective class habitus of their acceptance of white middle-class English language. In contrast, NNT7 mentioned that students did not necessarily prefer white NESTs, stating, "Students also seem to be interested in black NESTs. They are not hostile to black NESTs". NT10 indicated that NNEST's preferences for white NESTs did not reflect students' interests. She said, "I get the impression that teachers and parents always prefer white American female teachers. But from the students, I think they are just interested in anybody who is foreign". NNT4 and NNT5's statements highlight the strong racial prejudice among NNESTs, while students do not have such prejudice. This point may indicate that teachers infuse students with racial prejudice related to English standards. Interestingly, NT10's statement about teachers and parents' preference for white American female teachers implies that native-speakerism incorporates a typical model of the individual English teacher involving multiple social issues, including nation, ethnicity, class, and even gender.

Although NESTs have various types and levels of cultural capital, they are classified under one category-native speakers. This point indicates the double-edged sword of native-speakerism: while native-speakerism clearly distinguishes NESTs from NNESTs and gives NESTs socioeconomic powers, it blurs other cultural capitals of which some NESTs want to take advantage. In other words, the other forms of cultural capital that NESTs' may possess are ignored and they are perceived as belonging to just one category-NESTs-a category that even includes NESTs who do not possess actual linguistic capital (recent American citizens who are not actual native English speakers). Accordingly, native-speakerism may work to create the prejudice that NESTs possess only one cultural capital. This prejudice hinders some NESTs who possess other forms of cultural capital that might enable them to acquire the status of a professional teacher by developing their teacher identity and being accepted as English teachers by NNESTs and the teacher community.

\subsection{Native Speakerism as Symbolic Capital: NNESTs' Feelings of Their Inferior Teacher Status and Their Counterattack Through Institutional Cultural Capital}

Students' attitudes towards NESTs show how NESTs' linguistic capital presents as symbolic capital in the classroom. NESTs' native-speakerness as linguistic capital is highly valued by students and NNESTs recognize students' strong preference for NESTs. For example, NNT5 said, “To be honest with you, no matter how much I try, my students can still notice my Korean accent. Of course, they don't say it explicitly, but I can see their enthusiastic preference for NESTs in their eyes". NNT8 indicated that, because of students' preference for NESTs and NNESTs' lack of English-speaking competence, NESTs are mainly English teachers while NNESTs are classroom managers and illustrated this, "Students tend to pay attention when their NEST talks to them. When NNESTs are not confident with their English, NESTs take the full control of the class. In this case, NNESTs stand just at the back and NESTs teach from the beginning to the end". This example indicates how native-speakerness as symbolic capital in the classroom empowers NESTs as legitimate English teachers and disempowers NNESTs. The NNESTs clearly recognize their inferior status in the classroom and feel intimidated by NESTs. The permanent linguistic insecurity that NNESTs face exacerbates the perception of their inferior social status.

However, NNESTs perceive that students' prejudice in favor of NESTs may not be based on actual NESTs' competence as teachers but on mere native-speakerism. For example, NNT3 reported, 
"Students don't care whether their NESTs prepare for their classes or not. To the students, NESTs are perfect English teachers simply because they are native speakers of English". This example shows that NNESTs separate native-speakerness from the teaching competence that is perceived as NNESTs' strength. NNT3's statement implies that native-speakerness is overvalued and does not guarantee an effective English education.

NNT2 felt that students ignored her when she was with NESTs. NNT1 expressed her anxiety about the idea that students' prejudice in favor of NESTs may deprive her of authority and respect as a teacher and said,

"I am afraid of being compared with NESTs. What if my students think NESTs are better than I am? Students tend to think NNESTs are not legitimate English teachers. So, I sometimes find myself emphasizing that I am a tenured English teacher. For example, I tell them that I have the right to evaluate them. Students seem to think NNESTs are inferior to NESTs. So, I somehow imply that NESTs are temporary workers."

NNT1's statement offers an interesting example of how NNESTs feel about losing their power because students value the NESTs' linguistic capital which becomes a form of symbolic capital. This example clearly shows that NNESTs struggle to gain power with their institutional cultural capital (position as tenured teacher) against NESTs' linguistic capital by infusing students with the value of their tenured position.

Both NNT10 and NNT9 revealed how NESTs take advantage of the symbolic capital of native-speakerness to reproduce their dominant status in this field. NNT10 said, "NESTs consider themselves as the masters of English. They detest advice. Even when we try to say something, they don't like it". NESTs' authoritative behavior manifests the fact that the dominant party's linguistic habitus becomes the norm. NNT9 also reported a similar experience by saying, "There are some NESTs who are unhappy with my advice. They seem to think 'you speak poor English, so I don't need your help.' No matter how good or bad my English is, I have a sophisticated level of knowledge about teaching". This example demonstrates how NNESTs feel intimidated by this symbolic capital and try to highlight their strength-pedagogical knowledge.

Additionally, NNESTs raised the issue of NESTs' lack of teaching qualifications. NNT8 expressed her mistrust of NESTs' teaching quality and the effectiveness of NESTs' education and said, "Do we need to spend a lot of money on NESTs, which does not guarantee that NESTs will be effective? We don't have to bring NESTs who are unqualified. I think NESTs should be well trained. NNESTs are experts in English teaching. NESTs should be aware of the fact that speaking English and teaching English are two different things". NNT9's statement shows how NNESTs struggle to gain their power by valuing their cultural capital and devaluing NESTs'.

\subsection{Institutional Cultural Capital and Nests' Inferior Teacher Status}

The NESTs themselves recognize their limited institutional cultural capital, which comprises educational backgrounds, teacher certifications, and culturally appropriate pedagogical knowledge. Most NESTs in Korea are novice teachers, partly because the hiring process does not consider teaching experience or qualifications as essential criteria for job candidates. In particular, NESTs' lack of teaching training and experiences critically affects classroom management competence. Classroom management is reported to be the major concern for beginner teachers [69]. The NNESTs perceive that NESTs should not manage the classroom when co-teaching. NNT8 reported, "At the beginning of a semester, students often make trouble. So, I ask the NEST not to deal with the problem by himself and tell me. In fact, when the NEST is involved in handling troubles, a complaint could be raised. Moreover, the NEST does not deal with students' troubles in class very effectively". NNT3 gave an example of the lack of NESTs' classroom management skills by saying, "For example, NT6 is somewhat insensitive. He plays with the students during class until I must signal him to stop. He doesn't know how to behave in class". NNT4 pointed out her NT5 co-teacher's poor classroom management ability based on his lack 
of teaching training and experience. NT5 (NNT3's co-teacher) agreed that he lacked experience and classroom management competence, stating, "At first, I was letting the Korean teachers do all the classroom management. I guess I didn't have a whole lot of experience with children". NT2 also mentioned that classroom management is his weakness as an English teacher. NT4 clearly expressed the view that classroom management is NESTs' weakness but NNESTs' strength, and he relied entirely on NNESTs for discipline in class.

Interestingly, NNESTs brought up a language issue related to the classroom management, as when NNT10 reported, "I think it is more effective to use Korean rather than English teachers for class management. Talking in English repeatedly, 'Be quiet!' doesn't work. However, scolding in Korean just once works for the students". Because of the language issue, NT3 did not consider effective classroom management an achievable competence. This case of the particular language use for classroom management is very interesting, because it demonstrates how NNESTs' exclusive use of Korean language for student discipline reflects the power of NNESTs. This is the moment when NNESTs' tenured positions become the symbolic capital that leads NNESTs to dominate the classroom. The NESTs are not expected or encouraged to use Korean language during class, and indeed NESTs find it inappropriate to use Korean in English classes. For example, NT5 said, "I just think it's not helpful for the students to speak in Korean, especially when I am in the classroom". However, use of the Korean language by NNESTs, who are also English teachers for effective classroom management, may highlight an implicit agreement between NNESTs and students about NNESTs' exclusive teacher authority, thus revealing the social exclusion of NESTs from classroom politics or formal teacher-student relations. The issue of language in relation to classroom management can be serious as it can become an intrinsic weakness of NESTs that hinders the development of their professional teacher identities.

More than half of the NEST participants claimed that they usually let NNESTs manage the classroom as classroom management is beyond their competence, partly because they have limited understanding of the local educational culture and partly because they view themselves as unqualified and inexperienced. Since classroom management is considered an important part of teachers' competence in schools [70], the inability to control the classroom deprives them of teacher authority and autonomy as teachers. NT1 said, "I feel like the students are also not going to see you as an actual teacher if you are not managing the classroom like a teacher or if you are leaving it completely in the hands of your co-teacher". As expected, all NEST interviewees responded that students behave differently with NNESTs than with NESTs. NT3 commented, "They kind of treat me like I'm the same age as they are. I think my co-teacher is kind of the adult, and I'm kind of in the middle, and then the students are there". This shows that students perceive different levels of authority. NT10 mentioned the perceived inequality between NESTs and NNESTs, saying, "We don't have the same level of authority. Students know we are contract teachers, and NNESTs are tenure teachers". When asked why it matters to control class, NT7 answered, "because the students need to know that I'm a teacher too and that I also have authority". Thus, NESTs recognize that NNESTs' institutional cultural capital embodied in the tenured position emerges as symbolic capital in the classroom, and they feel inferior to NNESTs in terms of their status as teachers in the classroom.

The NESTs' lack of teacher authority, due to the fact of their insufficient classroom management competence, might seem to contradict previous interview data showing that students are enthusiastic about NESTs because of native-speakerism. Students' contradictory attitudes and behavior towards NESTs and NNESTs indicate the complexity of two different forms of symbolic capital (English-nativeness and classroom management by tenured teachers). Students may change their behavior and attitudes towards NESTs in different situations based on the form of symbolic capital highlighted; when students focus on English and foreigners (i.e., English-nativeness as symbolic capital is highlighted) they tend to be enthusiastic about NESTs and ignore NNESTs, while they submit to NNESTs' authority (i.e., classroom management by tenured teachers) and ignore NESTs when NNESTs have the power of student assessment. Symbolic capital provides the power to dominate the 
field. The NESTs and NNESTs, through their respective forms of symbolic capital, feel powerful and powerless simultaneously which confuses them and leads to power struggles.

\subsection{Collective Antagonistic Habitus and NESTs' Teacher Identities as Individualized Habitus}

The NESTs must teach with NNESTs and often they co-teach with several different NNESTs. For example, NT9 taught English grades 3-6 and had three different NNESTs. Thus, NESTs must negotiate the various teaching practices of different NNESTs. NT4 expressed confusion over his role in co-teaching since "everybody seems to have a wide variety of different ideas and styles". He reports this difficulty as follows: "It's really difficult. I am in that situation now because my two co-teachers are totally opposite in their styles, which is okay for me in a sense, but it's really hard to do this one set of things for one teacher and then to teach in a totally different style for another". NT2, who taught with five different NNESTs, describes this teaching arrangement as flawed since his five NNESTs have varying needs. When asked how he copes, he answered: "I try and let them be the boss". As NESTs are contract teachers without teacher training and local cultural knowledge, they mostly follow NNESTs' teaching styles and demands, which makes them perceive their co-teaching role as being teaching assistants rather than real teachers. NT1 expressed dissatisfaction with her role as an assistant in the classroom and seemed to think it unfair that NNESTs gave her no respect as a competent teacher when she has earned a good reputation for leading classes with high student satisfaction and taught in Korea more than four years. The NESTs' asymmetric power relationship with NNESTs in planning and organizing their teaching may be projected in their self-image as incompetent teachers and construct their fragmented teacher identity. This point is reflected by NT2's statement that he just follows his co-teachers' teaching styles.

Being employed without teacher training, NESTs imitated Korean co-teachers (NNESTs)' teaching styles and methods. NT3 said, "The first week that I was here, I observed my co-teacher teaching and I planned my lessons similar to the way she planned hers because I just learnt from her". As illustrated in the interview, many NESTs imitate NNESTs and NNESTs serve as role models for NESTs. Furthermore, NNESTs' vague guidelines are not useful for NESTs, particularly since most NESTs are novices. NT4 reported: "Like everyone else just always said from the beginning, 'whatever you want to do, just do it.' And I think that's a horrible way of telling someone to do their job. I think in the beginning, they should have told me what was expected of me, how to run the class, and how to do these things. I would just copy what they were doing sometimes, and they weren't doing the best job I think". NT4's case clearly shows a lack of communication and dissatisfaction with his Korean co-teachers' vague advice. The NNESTs and NESTs have different expectations about the other party's roles, and both seemed disappointed. As novice teachers, NESTs need sufficient communication about NNESTs' expectations for teaching methods, pedagogy, and students. Although co-teaching demands collaboration [71], NESTs and NNESTs do not seem to work together on lessons. NT6 reported: "Actually it's funny because I think we don't show each other our lesson plan until the day we are going to teach, and then we just show each other in the morning about $5 \mathrm{~min}$ before. I prefer that because it's just easy. But at the same time, I think I would want a little more preparation". NT6 reported that he hardly discussed lesson plans with his co-teachers. In general, collaboration and interactions for robust co-teaching were not carried out and both parties seemed to abandon such co-teaching. NT10 also said, "We [NT10 and her co-teachers] usually divide out the sections in the textbook. They always take reading or writing. I always take speaking. They must think that they should use me specifically for that". NNESTs did not try to hide the practical purpose of employing NESTs. For example, NNT3 sarcastically said, "Didn't we bring NESTs because of their expensive pronunciation?" and emphasized that "NNESTs are fully capable of teaching English without NESTs". NNT3's statement is a typical example of NNESTs' grievance against the policymakers' overestimation of NESTs' role in teaching English and their fear of losing their legitimacy which leads to their negative attitude towards NESTs.

The NNESTs expressed mistrust of NESTs' teaching quality and sense of responsibility because they thought that some NESTs regard teaching as just a way of earning money to pay for travel 
expenses. This point also results in NNESTs' negative attitude towards NESTs. Interestingly, most NEST interviewees were aware of this negative image of NESTs. NT2 commented on some irresponsible NESTs: "I will say that many foreigners are really bad at teaching and just live their lives because they go out and drink too much". The NEST interviewees tried to distance themselves from the widely perceived image of the irresponsible and unreliable NEST community. NT10 said, "Since I do care, it worries me. I don't want them [NNESTs] to think that I don't care about the job". NT4 reported that many NESTs who become teachers are mentally and pedagogically not prepared to teach and consequently disappoint NNESTs' expectations. NNT3 gave an example of NESTs' irresponsible behavior. She said, "He couldn't even explain his own PPT slides. It seemed that he downloaded the file and never practiced it. He has been late for school many times. He comes to class late." The NNESTs became prejudiced against NESTs through bad experiences, as NT8 and NT2 explained, which exacerbated the lack of communication and interaction. Under this prejudice, NESTs have few opportunities to prove themselves as teachers; they often remain subject to monitoring by NNESTs, contributing only as tools for pronunciation practice.

Teaching practices as habitus show distinct roles of NESTs as practical teaching tools focused on speaking and NNESTs as surveillants, which causes an antagonistic culture. This antagonistic habitus is exacerbated by the lack of interactions with NNESTs, since they are unable to establish co-teaching roles, as previously discussed. NT2 may have expected his Korean co-teacher to lead him as a mentor to become a competent teacher, and his co-teacher may have expected him to work as a competent teacher. These conflicts should have been fully explored and resolved through intensive communication between NESTs and NNESTs. NT2 said, "And she said 'Oh, I'm not your teacher, you should know how to do this because you have been doing this for a year and a half'. I said, 'Yeah, but you have been doing this for ten, so you should be able to show me how to do these things. If you know something better, then tell me.' But she actually is acting as a boss". NT4 mentioned a cultural difference that helps explain why NNESTs do not confront uncomfortable issues: "The funny thing about Korean culture is that people don't like to talk about their problems. They just want you to know it or they just get mad." As NESTs perceive NNESTs as boss, this culture of a lack of communication works as habitus in this field which discourages NESTs' communication motivations and activities.

Antagonistic collective habitus has developed as a result of unsatisfactory co-teaching roles, lack of interactions, different expectations, mistrust, negative attitudes, and cultural differences. Additionally, as the antagonistic collective habitus is originated by both NNESTs and NESTs' feelings of injustice, the antagonistic habitus seriously affects co-teaching relationships and practices. For example, NT6 made an interesting statement related to NNESTs' feelings of injustice: "Because it was one of those things where I think NNESTs have to do a lot more work to become a teacher as opposed to the foreigners who just kind of come here and don't really have to know anything but teach, so I think there is a little bit of jealousy from NNESTs". NESTs' feelings of injustice, as previously discussed, stem from the fact that they think they deserve to be treated as teachers and colleagues rather than as assistants.

The analysis result shows that NESTs' teacher identity ranges from "trained teacher" to "learner" based on whether they have the institutional cultural capital or not. NT4 portrayed himself as a "learner" who has an undergraduate degree in English. On the other hand, NT7 with a teacher certificate (BA degree in education) explicitly highlighted her teacher identity. NT8 described himself as a "trained British teacher" who obtained a teacher certificate (BA degree in education). Interestingly, both NT4 (34 months teaching in Korea) and NT8 (16 months teaching in the UK and 11 months in Korea) have around three years of teaching experience, and NT4 can be regarded as a more experienced teacher in Korean primary school. In comparison, NT7 (24 months teaching in Korea) has less teaching experience than NT4. However, the teacher certificate as institutional cultural capital rather than teaching experience seems to be a more important resource for NESTs' teacher identities. Only two out of ten NEST interviewees had teacher certificates. Some NEST interviewees were aware that they lack institutional cultural capital which makes them inferior in the social order and raised the issue of 
organizational inequality. For example, NT5 said, "I think it's more demotivating and unfair that you are not evaluated on progress but on the teacher certificates or degree you hold."

NT2 pointed out that many NESTs have not constructed their teacher identity and said, "The first month, I felt like I was just a tool, like something that you use on occasion". NESTs' negative self-images based on the lack of institutional cultural capital seem to increase their reliance upon their co-teachers and accept their inferior position, which is illustrated in the following extracts. NT4 said, "I'm not a teacher. I never studied education in my university. I'm just trying to learn as I go". NT4's identity as a learner seems to reflect his inferior position, which leads to passive interactions with co-teachers and subordinates him to them, since NT4 said that whenever he and his co-teachers have conflicts, he abandons discussions with them and follows their lead. Sometimes, if his views on discipline differ, he keeps silent.

Interestingly, all NEST interviewees emphasized their role as entertainers for students. The NEST interviewees used several metaphors to describe this particular role, including "game host", "cartoon character", and "trained monkey". NT5 commented, "In front of my students, I'm basically a mixture between a cartoon character and a game show host". This is related to NESTs' identities as "teacher without authority". The metaphors show NESTs' dissatisfaction with being devalued in the classroom, their lack of authority, and their identity as incompetent teachers.

\section{Discussion and Conclusions}

This study investigated expatriate NESTs' teacher identities as individualized habitus and collective habitus during their co-teaching practices as well as their interactions and power conflicts with NNESTs within Bourdieu's concepts of field, capital, and habitus. In identity literature, expatriate NESTs have received less attention than NNESTs in terms of power conflicts and teacher identity. As most NESTs in Korea do not have institutional cultural capital, they may experience themselves as second-class citizens which impedes their construction of teacher identity. NESTs' relationships with NNESTs may embody dynamic power conflicts in their co-teaching contexts, since NNESTs who regard NESTs as threats to their profession try to keep their vested rights in the classroom and organization. Thus, power struggles between NESTs and NNESTs in producing and reproducing superior social status in the field of English teaching are apparent, because they possess different cultural capitals that become symbolic capitals in the classroom.

The interview analysis found that the two symbolic capitals create complexity in power. One symbolic capital is based on native-speakerism as the prevalent ideology in the field of English teaching, and the other is the tenured teacher position based on institutional cultural capitals. Our data show the role of native-speakerism as the linguistic capital that NESTs distinctively possess and as a guiding ideology of practice that shapes both NNESTs and students' attitudes towards NESTs and produces values, meanings, and norms in this field. The data reveal that native-speakerism causes NNESTs' permanent linguistic insecurity. Native-speakerism in combination with values and shared beliefs fortifies social inequality by reproducing NESTs' domination in this field. Native-speakerism combined with white middle-class English as the norm works as a collective class habitus and creates three classes: white middle-class NESTs, non-white middle class NESTs, and NNESTs. Additionally, native-speakerism is a double-edged power for NESTs, giving them power over NNESTs based on linguistic capital but also branding NESTs as unqualified and incompetent teachers who lack proper institutional cultural capital. On the other hand, the tenure-contract distinction based on institutional cultural capital causes NESTs' institutional insecurity, and they perceive themselves as unqualified teachers. Their institutional insecurity makes them depend on NNESTs and limits their role as specific linguistic tools. Each form of symbolic capital provides power to dominate the field and reproduce superior social status; however, each form of symbolic capital also deprives the rival of a sense of security. Accordingly, NESTs feel empowered through their linguistic symbolic capital but suffer institutional insecurity based on their lack of institutional cultural capital as symbolic capital, while NNESTs are empowered through their institutional cultural capital but suffer from linguistic insecurity. 
Thus, symbolic capitals make both NESTs and NNESTs simultaneously enjoy relative power and suffer from a sense of relative deprivation.

According to the data analysis, power conflicts seem to involve processes that are not necessarily linear: first, noticing or acknowledging that the other party's cultural capital has become symbolic capital and that students follow the power of symbolic capital; second, being anxious about losing one's own power and falling into an inferior status; and third, trying to value one's own cultural capital and devalue the other party's to maintain a superior social status. The NNEST interviewees felt threatened by NESTs' linguistic capital and expressed their anxiety about losing their legitimacy and authority upon noticing students' enthusiasm and preference for NESTs. They valued their institutional cultural capital and reminded students of the authority that tenured teachers hold to evaluate students. The NNEST interviewees expressed dissatisfaction about the policy of recruiting NESTs and want to discard the policy.

On the other hand, according to the NEST interviewees, their limited role in classroom management makes them insecure about their teacher authority, which in turn makes them feel incompetent and dependent on NNESTs. Their self-perception of being unqualified contract teachers not only limits classroom management but also makes them subordinate to NNESTs. Their anxiety about their lack of institutional cultural capital makes them feel unequal to NNESTs, as that lack diminishes their authority. In the classroom, NEST interviewees revealed that students denied NESTs' teacher authority when they followed NNESTs' authority, since students perceived their asymmetric power relationships. The NEST interviewees expressed dissatisfaction about their roles and constructed disrupted or fragmented teacher identities.

Teaching practices as habitus show a division of roles-between NESTs as practical teaching tools focused on speaking and NNESTs as surveillants based on mistrust—as well as a disappointment with each other's roles in co-teaching practices and a lack of interaction, which result in distorted, fragmented, and disconnected co-teaching between the teachers. These ill-matched co-teaching practices cause an antagonistic collective habitus that in turn exacerbates the fragmented and disconnected co-teaching that lacks proper collaboration and interactions among co-teachers. The habitus is thus continuously produced and reproduced.

The NNESTs' grievance against the policymakers' overestimation of the NESTs' role in teaching English and fear of losing the legitimacy of their English teacher positions lead them to form negative attitudes towards NESTs. The NESTs feel that they are unfairly treated by NNESTs because NNESTs do not appreciate their teaching leadership and efforts in the classroom and treat them as teaching assistants or specialized linguistic tools rather than as real teachers or colleagues. Antagonistic collective habitus between NESTs and NNESTs in this field resulted in negative aspects in co-teaching practices. Additionally, arising from the feelings of injustice or unfairness on the part of both NNESTs and NESTs, the antagonistic collective habitus seriously affects co-teaching relationships and practices. The division of roles in the co-teaching practice does not create synergism but instead leads to NESTs' fragmented teacher identities as functional teachers without authority and respect, while NNESTs experience insecurity and anxiety. Because of the complexity of their power relations, NESTs experience a power rollercoaster from being the most legitimate English teacher to working as a classroom assistant, depending on the operation of the two symbolic capitals. NESTs seem to suffer from their fragmented teacher identity by serving trained monkeys working between the trainer (NNESTs) and the audience (students) or as classroom assistants who feel betrayed because they believe that they are employed as teachers.

Our interview data demonstrate the interrelatedness of Bourdieu's three pillar concepts. The English teaching field creates a shared belief in and norm of two forms of symbolic capital; however, under the condition of two forms of symbolic capital divided between the NESTs and NNESTs, this field has become a battlefield where NESTs and NNESTs, loaded with their symbolic capital as weapons, struggle to gain power, legitimacy, field domination, and superior status. Their power struggle shapes 
the fragmented teacher identities caused by linguistic and institutional insecurities as individualized habitus and antagonistic collective habitus.

Thus, we argue that the sociological frameworks of Bourdieu's concepts might provide novel insights into understanding the NESTs' power rollercoaster (i.e., extreme shifts of power) and the nature of the power struggle between NESTs and NNESTs. Bourdieu's concepts of field, capital, and habitus provide a sociological vocabulary for the illumination and analysis of NESTs' teacher identities and social status trajectories. This study shows that NESTs' difficulties in constructing teacher identities increase their dissatisfaction with their current roles as well as NNESTs' insecurity and fragmented teacher identities. Interestingly, the NEST interviewees expressed having experienced a healing process during the interview, which highlights their considerable distress. This exploratory study is a rare piece of empirical research that shows the relational effects of Bourdieu's three concepts on NESTs and NNESTs' teacher identities and collective habitus in the field of English teaching. This study provides an important implication for theory and policy—that the English education practices and policies based on the ideology of native-speakerism fortify students' preference for native English and negative attitudes towards localized variants of English, which threatens not only linguistic and cultural diversities of non-native localized variants of English and their sustainability but also NNESTs' teacher identities. To address problems with the application of native-speakerism ideology to ELT policies and practices, a commonly recommended proposal is that a localized model, linguistically, culturally and politically more effective to English teachers and learners in the local context, should be applied instead of a native speaker model [8]. Our research findings strongly recommend that Korean ELT policy should first develop an effective localized ELT model, and find a way to integrate the localized model in ELT practices. Additionally, further studies investigating students' preference for NESTs can produce useful implications to establish an effective localized ELT model.

Author Contributions: K.H. and S.Y.Y. developed conceptualization and methodology, S.Y.Y. interviewed the participants, K.H. and S.Y.Y. performed formal analysis, K.H. performed writing-original draft preparation, and K.H. and S.Y.Y. did writing-review and editing.

Funding: This research received no external funding.

Conflicts of Interest: The authors declare no conflict of interest.

\section{References}

1. McKay, S.L. Toward an appropriate EIL pedagogy: Re-examining common ELT assumptions. Int. J. Appl. Linguist. 2003, 13, 1-22. [CrossRef]

2. Modiano, M. Linguistic imperialism, cultural integrity, and EIL. ELT J. 2001, 55, 339-346. [CrossRef]

3. Shin, J.; Eslami, Z.R.; Chen, W.C. Presentation of local and international culture in current international English-language teaching textbooks. Lang. Cult. Curric. 2011, 24, 253-268. [CrossRef]

4. Tokumoto, M.; Shibata, M. Asian varieties of English: Attitudes towards pronunciation. World Engl. 2011, 30, 392-408. [CrossRef]

5. McKenzie, R. Social factors and non-native attitudes towards varieties of spoken English: A Japanese case study. Int. J. Appl. Linguist. 2008, 18, 63-88. [CrossRef]

6. Timmis, I. Native-speaker norms and international English: A classroom view. ELT J. 2002, 56, 240-249. [CrossRef]

7. Kabel, A. Native-speakerism, stereotyping and the collusion of applied linguistics. System 2009, 37, 12-22. [CrossRef]

8. Wang, W. Teaching English as an international language in China: Investigating university teachers' and students' attitudes towards China English. System 2015, 53, 60-72. [CrossRef]

9. Guo, Y.; Beckett, G.H. The hegemony of English as a global language: Reclaiming local knowledge and culture in China. Convergence 2007, XL, 117-131.

10. Nunan, D. The impact of English as a global language on educational policies and practices in the Asia-Pancific region. TESOL Q. 2003, 37, 589-613. [CrossRef] 
11. Wang, L.-Y.; Lin, T.-B. The representation of professionalism in native English-speaking teachers recruitment policies: A comparative study of Hong Kong, Japan, Korea and Taiwan. Engl. Teach. 2013, 12, 5-22.

12. Yim, S.Y.; Hwnag, K. Expatriate ELT teachers in Korea: Participation and sense of belonging. ELT J. 2019, 73, 72-81. [CrossRef]

13. Malm, B. Towards a new professionalism: Enhancing personal and professional development in teacher education. J. Educ. Teach. 2009, 35, 77-91. [CrossRef]

14. Carless, D.R. Good practices in team teaching in Japan, South Korea and Hong Kong. System 2006, 34, 341-351. [CrossRef]

15. Richards, J.C. Competence and performance in language teaching. RELC J. 2010, 41, 101-122. [CrossRef]

16. Wang-McGrath, S.-C. The role of faith in the power balance between Christian native speakers and Taiwanese teachers who team teach. In ELT and Christian Faith; Shepard Wong, M., Dornyei, Z., Kristjansson, C., Eds.; Routledge: London, UK, 2013; pp. 31-46.

17. Varghese, M.; Morgan, B.; Johnston, B.; Johnson, K.A. Theorizing Language Teacher Identity: Three Perspectives and Beyond. J. Lang. Identity Educ. 2005, 4, 21-44. [CrossRef]

18. Jeon, M. Globalization and native English speakers in English Programme in Korea (EPIK). Lang. Cult. Curric. 2009, 22, 231-243. [CrossRef]

19. Kim, S. Living as a welcomed outsider: Stories from native English speaker teachers in Korea. Korea J. Appl. Linguist. 2012, 28, 27-58. [CrossRef]

20. Yeom, M.; Ginsburg, M. Professionalism and the reform of teachers and teacher education in the Republic of Korea \& the United States of America. Asia Pac. Educ. Rev. 2007, 8, 298-310.

21. Kurunmäki, L. Professional vs financial capital in the field of health care-Struggles for the redistribution of power and control. Account. Organ. Soc. 1999, 24, 95-124. [CrossRef]

22. Morrison, K.; Lui, I. Ideology, linguistic capital and the medium of instruction in Hong Kong. J. Multiling. Multicult. Dev. 2000, 21, 471-486. [CrossRef]

23. Diniz de Figueiredo, E.H. Nonnative English-speaking teachers in the United States: Issues of identity. Lang. Educ. 2011, 25, 419-432. [CrossRef]

24. Schaefer, L. Beginning teacher attrition: A question of identity making and identity shifting. Teach. Teach. 2013, 1-15. [CrossRef]

25. Trent, J. The discursive positioning of teachers: Native-speaking English teachers and educational discourse in Hong Kong. TESOL Q. 2012, 46, 104-126. [CrossRef]

26. SukYang, J. The comparative analysis on students' perception about Korean and native English teachers. Foreign Lang. Educ. 2012, 19, 25-49.

27. Bourdieu, P.; Wacquant, L.J. An Invitation to Reflexive Sociology; University of Chicago press: Chicago, IL, USA, 1992.

28. Bourdieu, P. The Logic of Practice; Stanford University Press: Palo Alto, CA, USA, 1990.

29. Everett, J. Organizational research and the praxeology of Pierre Bourdieu. Organ. Res. Methods 2002, 5, 56-80. [CrossRef]

30. Bourdieu, P. Language and Symbolic Power; Polity Press: Cambridge, UK, 1991.

31. Bourdieu, P.; Passeron, J.-C. Reproduction in Education, Society and Culture; Sage: London, UK, 1990; Volume 4.

32. Bourdieu, P. The force of law: Toward a sociology of the juridical field. Hastings LJ 1986, 38, 805.

33. Meisenhelder, T. The developmental state in Mauritius. J. Mod. Afr. Stud. 1997, 35, 279-297. [CrossRef]

34. Swartz, D.L. Bringing Bourdieu's master concepts into organizational analysis. Theory Soc. 2008, 37, 45-52. [CrossRef]

35. Bourdieu, P. Outline of a Theory of Practice; Cambridge University Press: Cambridge, UK, 1997.

36. Leaton Gray, S.; Whitty, G. Social trajectories or disrupted identities? Changing and competing models of teacher professionalism under New Labour. Camb. J. Educ. 2010, 40, 5-23. [CrossRef]

37. Jenkins, R. Pierre Bourdieu, Key Sociologists; Routledge: London, UK, 1992.

38. Rex, L.A.; Nelson, M.C. How teachers' professional identities position high-stakes test preparation in their classrooms. Teach. Coll. Rec. 2004, 106, 1288-1331. [CrossRef]

39. Bourdieu, P. Social space and symbolic power. Sociol. Theory 1989, 7, 14-25. [CrossRef]

40. Chan, E. Beyond pedagogy: Language and identity in post-colonial Hong Kong. B. J. Sociol. Educ. 2002, 23, 271-285. [CrossRef] 
41. Reay, D. 'It's all becoming a habitus': Beyond the habitual use of habitus in educational research. Br. J. Sociol. Educ. 2004, 25, 431-444. [CrossRef]

42. Atkin, C. Lifelong learning-attitudes to practice in the rural context: A study using Bourdieu's perspective of habitus. Int. J. Lifelong Educ. 2000, 19, 253-265. [CrossRef]

43. Nash, R. The educated habitus, progress at school, and real knowledge. Interchange 2002, 33, 27-48. [CrossRef]

44. Dumais, S.A. Cultural capital, gender, and school success: The role of habitus. Sociol. Educ. 2002, 75, 44-68. [CrossRef]

45. Braine, G. Non-native Educators in English Language Teaching; Routledge: New York, NY, USA; London, UK, 2013.

46. Brutt-Griffler, J.; Samimy, K.K. Revisiting the Colonial in the Postcolonial: Critical Praxis for Nonnative-English-Speaking Teachers in a TESOL Program. TESOL Q. 1999, 33, 413-431. [CrossRef]

47. Pavlenko, A. "I Never Knew I Was a Bilingual”: Reimagining Teacher Identities in TESOL. J. Lang. Identity Educ. 2003, 2, 251-268. [CrossRef]

48. Lippi-Green, R. English with an Accent: Language, Ideology, and Discrimination in the United States; Psychology Press: East Sussex, UK, 1997.

49. Ryu, K.; Choi, S.; Kim, B.A. A ethnographical research on the school life of the elementary school's period-limit teachers. J. Res. Educ. 2011, 41, 121-147.

50. Govinda, R.; Josephine, Y. Para teachers in India: A review. Contemp. Educ. Dialogue 2005, 2, $193-224$. [CrossRef]

51. Genzuk, M.; Lavadenz, M.; Krashen, S. Para-educators: A source for remedying the shortage of teachers for limited-English-proficient students. J. Educ. Issues Lang. Minor. Stud. 1994, 14, 211-222.

52. Norton, B. Identity and Language Learning: Gender, Ethnicity and Educational Change; Longman: New York, NY, USA, 2000.

53. Zembylas, M. Emotions and Teacher Identity: A poststructural perspective. Teach. Teach. 2003, 9, $213-238$. [CrossRef]

54. Foucault, M. POWER/KNOWLEDGE: Selected Interviews and Other Writings 1972-1977; Gordon, C., Ed.; Pantheon: New York, NY, USA, 1980.

55. Tsui, A.B.M. Complexities of identity formation: A narrative enquiry of an EFL teacher. TESOL Q. 2007, 41, 657-680. [CrossRef]

56. Tajino, A.; Tajino, B. Native and non-native: What can they offer? ELT J. 2000, 54, 3-11. [CrossRef]

57. Kim, S.H.; Kwak, B.K. The effects of the native English teacher program on high school English education. Foreign Lang. Educ. 2002, 9, 211-241.

58. Forrester, V.; Lok, B. Native English teachers in Hong Kong: Building communication of practice? Asian Soc. Sci. 2008, 4, 3-11. [CrossRef]

59. Kwon, M.; Kellogg, D. Teaching talk as a game of catch. Can. Mod. Lang. Rev. 2005, 62, 335-348. [CrossRef]

60. Chen, C.W.-Y.; Cheng, Y.-S. A case study on foreign English teachers' challenges in Taiwanese elementary schools. System 2010, 38, 41-49. [CrossRef]

61. Verity, D.P. Side affects: The strategic development of professional satisfaction. In Sociocultural Theory and Second Language Learning; Lantolf, J.P., Ed.; Oxford University Press: Oxford, UK, 2000; pp. 179-197.

62. Kachru, B.B. Standards, codification and sociolinguistic realism: The English language in the outer circle. In English in the World: Teaching and Learning the Language and Literature; Quirk, R., Widdowson, H., Eds.; Cambridge University Press: Cambridge, UK, 1985; pp. 11-36.

63. Holliday, A.R. Native-speakerism: Taking the concept forward and achieving cultural belief. In Native-speakerism and Shifting Perspectives; Swan, A., Aboshiha, P.J., Holliday, A.R., Eds.; Palgrave: London, UK, 2015; pp. 9-19.

64. Leech, N.L.; Onwuegbuzie, A.J. Beyond constant comparison qualitative data analysis: Using NVivo. School Psychol. Q. 2011, 26, 70-84. [CrossRef]

65. Fielding, N.; Lee, R.M. Computer Analysis and Qualitative Research; Sage: London, UK, 1998.

66. Merriam, S.B. Qualitative Research and Case Study Applications in Education, 2nd ed.; Jossey-Bass: San Francisco, CA, USA, 1998.

67. James, N. Emotional labour: Skill and work in the social regulation of feelings. Sociolog. Rev. 1989, 37, 15-42.

68. Bourdieu, P. The economics of linguistic exchanges. Information (Int. Soc. Sci. Counc.) 1977, 16, 645-668. [CrossRef] 
69. Veenman, S. Perceived problems of beginning teachers. Rev. Educ. Res. 1984, 54, 143-178. [CrossRef]

70. Stoughton, E.H. "How will I get them to behave?": Pre service teachers reflect on classroom management. Teach. Teach. Educ. 2007, 23, 1024-1037. [CrossRef]

71. Carless, D.; Walker, A. Effective team teaching between local and native-speaking English teachers. Lang. Educ. 2006, 20, 463-477. [CrossRef]

(C) 2019 by the authors. Licensee MDPI, Basel, Switzerland. This article is an open access article distributed under the terms and conditions of the Creative Commons Attribution (CC BY) license (http://creativecommons.org/licenses/by/4.0/). 